\title{
A decision-making process to undergo orthodontic treatment: a qualitative study
}

This article was published in the following Dove Press journal:

Patient Preference and Adherence

\begin{abstract}
Mohammad Moslem Imani'
Amir Jalali ${ }^{2,3}$

Ebraheim Ezzati ${ }^{4}$

Zeinab Heirani ${ }^{5}$

Mohammadreza

Dinmohammadi ${ }^{6}$

'Department of Orthodontics, Faculty of Dentistry, Kermanshah University of Medical Sciences, Kermanshah, Iran; ${ }^{2}$ Department of Psychiatric Nursing, School of Nursing and Midwifery, Kermanshah University of Medical Sciences, Kermanshah, Iran; ${ }^{3}$ Substance Abuse Prevention Research

Center, Kermanshah University of Medical Sciences, Kermanshah, Iran; ${ }^{4}$ Anesthesiology Medical Department, School of Paramedical Kermanshah, University of Medical Sciences, Kermanshah, Iran; ${ }^{5}$ Department of Psychiatric Nursing, School of Nursing and Midwifery, Kermanshah University of Medical Sciences, Kermanshah, Iran; ${ }^{6}$ Department of Nursing, School of Nursing and Midwifery, Zanjan University of Medical Sciences, Zanjan, Iran
\end{abstract}

Background: Orthodontics is a medical treatment and a rehabilitation service provided for individuals in need. Due to the high cost involved in performing this type of treatment along with the current attitude in communities toward it as a cosmetic service, it is essential to investigate the decision-making process to undergo orthodontic interventions among Iranian individuals and families.

Methods: To conduct this qualitative study using grounded theory, 18 participants were selected through purposive sampling method and received semi-structured interviews each lasting 50-70 minutes. Eventually, the data were saturated after the fulfillment of 19 interviews. During the interviews, simultaneous analysis was also performed according to the method proposed by Strauss and Corbin (1998) and then the data were analyzed within three stages of open, axial, and selective coding.

Results: Analysis of the clients' statements produced 207 codes, 22 sub-categories, and 9 main categories, including distorted mental self-image, hope to look more attractive, inappropriate interactions with family and those around, family's views toward the problem, social conditions, financial constraints, challenges in the family, as well as decision making to undergo orthodontic treatment, and finally, the main factor of hope for a better future were highlighted.

Conclusion: The results showed that the main facilitating factor was "hope for a better future" for which families could accept numerous difficulties, such as high cost and repeated follow-ups due to the importance of beauty and meeting their children's sense of satisfaction.

Keywords: orthodontics, grounded theory, decision making, esthetics

\section{Background}

The effects and complications of oral and dental diseases can have psychological and social dimensions influencing mental health status in individuals. ${ }^{1}$ For more than a decade, oral health and diseases, the appearance, malocclusion, and malposition of teeth, and treatment and correction of such maladjustments have been considered among the important factors affecting the mental status and well-being in individuals. Moreover, these factors have also been considered as growing concerns among therapists and researchers. ${ }^{2}$ Although malocclusion is not recognized as a disease, many individuals assume it as a deviation from the norm of beauty. ${ }^{3}$ In addition to tooth alignment, orthodontics can improve the health of the teeth and the gums and also numerous malpositioned teeth and jaws that can be treated and corrected using orthodontic instruments. ${ }^{4}$ It is commonly expected that orthodontic treatments can increase the quality of life in people affected with malocclusion. In this regard, studies have shown that in cases with mild or moderate disorder, orthodontic treatments have had greater effect on the quality of life compared with those for severe ones. ${ }^{5,6}$ 
Since orthodontic treatment can directly lead to a change in clients' appearance and their facial features, orthodontists are required to recognize the underlying issues of social psychology and the theory of facial attractiveness. ${ }^{1}$ Accordingly, Caglayan et al believed that the need for orthodontic treatment had considerably affected the quality of life of school children, but reported no impact on their daily living and psychosocial activities. ${ }^{7}$ It is also of note that orthodontic treatments have grown exponentially in order to improve the arrangement of the teeth and esthetics as well as facial beauty. ${ }^{6}$

Today, orthodontics is greatly considered as a successful and appropriate treatment to improve the adjusted position of the teeth and increase physical attractiveness in communities. ${ }^{8}$ In this respect, decision making to undergo orthodontics can be based on the artificial neural networks model and according to examinations and assessments conducted by specialists. ${ }^{9}$ To choose therapeutic methods, especially surgery, interactions between orthodontists and clients are of paramount importance and decisions to choose the type of treatment depends on these proper interactions. Accordingly, two factors can influence interactions and decision making to opt for a treatment; first, how individuals can become aware of their disease conditions and various types of effective therapies available; and second, therapists' awareness of expectations and attitudes in clients toward themselves as well as treatments. ${ }^{10}$

According to Kazanci et al, family members, especially mothers, can play a very important role in deciding whether orthodontics is carried out or not; however, parents' and clients' concerns about orthodontic treatment as well as its effects on self-esteem, attitudes, beauty, and oral health should also be taken into account. ${ }^{11}$ In addition, family support and influence of opinions and attitudes by family members are recognized as very important factors that can affect the decision-making process to receive such a treatment. Among other factors that can affect this type of treatment is clients' cultural and economic status. Besides, orthodontics has been accepted among individuals as a cosmetic treatment while, in many cases, this type of treatment can contribute to improving the quality of life in individuals and lead to their better nutrition. ${ }^{1}$ In order to implement the best decision, you have to understand the views of relevant people as well as important factors influencing their decision making. ${ }^{12}$ Expectations, views, and attitudes of clients and parents are also of utmost importance in deciding whether to perform orthodontics or not. ${ }^{11}$ Hence, the best method to understand the reasons behind the selection of this therapeutic approach is the clarification of this issue from the words of the people involved. Given the investigation into the decision-making process and the reasons affecting it, the best research method in this regard is the qualitative studies. ${ }^{13}$ Within this research type, the researcher is able to analyze participants' statements and then report their experiences regarding the phenomenon examined from their own words. ${ }^{14}$ There are different types of qualitative research studies that are used to describe and understand the key structure of the sociological and psychological processes employed in today's world. ${ }^{15}$ Different methods are similarly used in qualitative research, including grounded or base theory. According to the studies cited, orthodontic services are known as costly and expensive ones demanded by individuals with a high cultural and economic status. Using a qualitative research method via the grounded theory approach, the present study investigates the decisionmaking process to use orthodontics. Meanwhile, strategies are presented for policy-makers to encourage the clients who need this treatment along with the determination of existing facilitators and barriers to select this method.

\section{Methods \\ Design}

This qualitative study was conducted based on the grounded theory.

\section{Setting}

The research context included private orthodontic clinics in the city of Kermanshah, Iran.

\section{Participants}

The study participants were selected from different age groups in both genders. Appropriate physical and psychological conditions during the interview, history of using orthodontic treatment (clients undergoing fixed orthodontic treatment who had only the problem of malocclusion with normal jaws and proportions of the face), willingness to participate in the study, ability to speak, age range between 14 and 45 years, and completion of informed consent form were among the inclusion criteria in this study. In addition, important and influential family members, as well as dentists with working experience in orthodontic clinics affecting the decision-making process were selected and interviewed.

\section{Data collection}

The data needed in this study were collected using a semi-structured and in-depth interview containing 
open-ended questions. The main interviews were conducted by the second author in-person on different occasion (in the morning and at night) in clinics or places decided by clients that they deemed were proper and calm. The interviews were also recorded upon the participants' agreement. In addition, note-taking during interviews were used in a way that voice tone, word pronunciations, laughs, cries, and pauses produced by the participants were considered during the interviews. The average time considered for each interview was 50-70 minutes. To facilitate the data collection, guided questions were used during the interviews.

\section{Guided questions included}

1. How did you choose to use orthodontics?

2. What happened to choose this treatment since you felt what you needed?

3. Who was involved in your decision making?

4. In your opinion, what are the problems for those who decide to choose this method?

5. Who can help with making decisions to use orthodontics? How?

\section{Data analysis}

To analyze the data in this study, the method proposed by Strauss and Corbin was utilized. ${ }^{14}$ The main stages of this method include open, axial, and selective coding. In this research, interviews were listened to carefully and repeatedly. Then, they were manually transcribed verbatim in the Office Word 2010 Software. The transcribed interviews were reread and then open coding was conducted. At this stage, the codes were selected from the words and sentences contained in the participants' interviews. All the interviews were also immediately analyzed by the second author simultaneously after their completion. Afterward, the researcher studied and compared the extracted codes continuously and specified the common points and differences. Next, codes with similar characteristics were placed in the same category. The categorization of the codes at this stage was the start of axial coding. The process of continuous comparison of the data, their movements among category, and insertion of new codes into certain category considering their resemblance or difference with other codes were also carried out in all steps of data analysis. The continuous comparison of the extracted codes and category could contribute to the categorization and insertion of each new code. As a result, the formation method of category and the appropriate category for the insertion of the codes changed continuously. Eventually, this process led to the creation of category and their adjustment or combination to form new ones. All steps of the analysis were carried out by manual method and without any qualitative analysis software.

Furthermore, a storyline was used in order to integrate and purify the analysis of data, discover the main concepts, reach the core variable, and explore the relationship between the categories. The occurring process was also written in the form of a storyline using descriptive sentences. When writing the storyline, the effects of the main or the core factor were examined repeatedly by referring to the raw data, participants' interviews, and the category extracted from the study.

The main factor was also investigated and explored by the researcher through examining the data, administering repeated interviews, and raising questions like "What is happening?", "What are the main problems for the participants?", and "What have they done to solve them?". In this study, the researcher could discover the relationship between the category and the sub-category, review the findings continuously, and find that "hope for a better future". As the core variable was associated with the clients and, to some extent, with their families from the onset of the process, the given process could begin from a distorted mental self-image until the occurrence of decision making phenomenon for the use of orthodontic treatment. The participants referred to this core variable in their interviews implicitly and repeatedly.

\section{Truthfulness}

To ensure the accuracy and the reliability of the data, four criteria of trustworthiness (credibility, confirmability, dependability, and transferability) proposed by Guba and Lincoln (1985) were used. ${ }^{13}$ In this way, the researcher was in a long-term contact with the research context during the study (the second author was interacting with the related clients for many years). Moreover, the first and the second authors interacted with the study participants via telephone conversations, which, in turn, could win their trust and lead to a good understanding of the research environment. To review the data and the codes extracted from the interviews with the participants, several meetings were held in the presence of the first and the second authors. In this process, the transcribed interviews were returned to the participants after coding to obtain the accuracy of the codes and ensure their interpretations. Therefore, the codes that could not explain the participants' attitudes were removed. Moreover, the sampling method could cover a wide range 
of clients, their family members, and therapists in terms of age, gender, and working experience in the related field, leading to the increased credibility of the data. Some transcribed interviews were also reviewed by other researchers familiar with qualitative studies; that is, the codes and the category extracted were not only reviewed by the main authors but also examined by several related researchers.

\section{Ethical considerations}

After obtaining the letter of permission from Kermanshah University of Medical Science Ethical Committee (KUMS. REC.1395.110), a written informed consent form was prepared, and then completed and signed by the researchers and the participants after providing brief and clear explanations about the given form. The participants were also informed and all them had agreed to recording of the interview. The participants were also assured about the confidentiality of the data; that is, the data would not be available to anyone except the study researcher. The participants' names also remained anonymous and only the researchers and the participants themselves could see them. The participants were also allowed to withdraw from the study at any stage they desired. Also, a parent or legal guardian provided written informed consent for any participant under the age of 18 years.

\section{Results}

In this study, a total of 19 interviews were conducted with 18 participants (15 clients, a mother, a father, and an orthodontist). The demographic characteristics of the patients participating in the study are illustrated in Table 1.

According to the analysis of the participants' statements, 291 initial codes were obtained. After continuous reviews and removal of duplicate codes, a total of 207 codes, 22 subcategories, and 9 main categories were obtained (Table 2).

\section{Categories and sub-categories Distorted mental self-image}

The problem of malpositioned teeth and contact with those who had undergone orthodontic treatment and become more attractive had led the clients to believe their appearance was defective. It also made them exaggerate their facial disproportion and problems in jaw structures. All these could lead to psychological tensions and a distorted mental self-image. In this regard, clients said that:

Every day, I used to get familiar with my appearance by looking at myself in the mirror, I hated myself. My teeth were misaligned. I was afraid to laugh and open my mouth. I thought that all my friends would ridicule me if I smiled or laughed [...]. [P1]

Every day as I woke up, I did not want to leave the bed. I always spoke with myself saying that how I could go out with such an awful appearance because I could not speak well [...]. [P3]

\section{Hope to look more attractive}

This was one of the factors emphasized by all the study participants. The analysis of the statements of clients showed a

Table I Demographic characteristics of the patients participating in the research

\begin{tabular}{|c|c|c|c|c|c|c|}
\hline No & Gender & $\begin{array}{l}\text { Age } \\
\text { (years) }\end{array}$ & $\begin{array}{l}\text { Marital } \\
\text { status }\end{array}$ & $\begin{array}{l}\text { Cause of orthodontic } \\
\text { procedure }\end{array}$ & Educational level & Father/spouse job \\
\hline I & $\mathrm{F}$ & 21 & Single & Upper teeth protrusion & BSc & Employee \\
\hline 2 & $M$ & 19 & Single & Maladjusted jaws & BSc & Driver \\
\hline 3 & $M$ & 17 & Single & Two teeth overlapped & High school & Teacher \\
\hline 4 & $M$ & 24 & Single & Malaligned teeth & BSc & Employee \\
\hline 5 & $\mathrm{~F}$ & 22 & Married & Overlapped teeth & Diploma & Business man \\
\hline 6 & $M$ & 14 & Single & My teeth were not aligned & High school & Employee \\
\hline 7 & $\mathrm{~F}$ & 15 & Single & One of my teeth was tilted & High school & Worker \\
\hline 8 & $\mathrm{~F}$ & 14 & Single & Rabbit teeth & High School & Employee \\
\hline 9 & $\mathrm{~F}$ & 14 & Single & Excessive tooth show on smile & High school & Worker \\
\hline 10 & $M$ & 19 & Single & The teeth were on each other & Diploma & Driver \\
\hline II & $M$ & 17 & Single & Upper jaw was protruded & Student & Employee \\
\hline 12 & $\mathrm{~F}$ & 27 & Single & Crowded teeth & Diploma & Worker \\
\hline 13 & $\mathrm{~F}$ & 22 & Single & My teeth were protruded & Diploma & Employee \\
\hline 14 & $\mathrm{~F}$ & 24 & Married & Teeth protrusion while smiling & Student & Employee \\
\hline 15 & $\mathrm{~F}$ & 17 & Single & Malaligned teeth & Diploma & Worker \\
\hline
\end{tabular}


Table 2 Categories and sub-categories

\begin{tabular}{|c|c|c|}
\hline & $\begin{array}{l}\text { General } \\
\text { category (9) }\end{array}$ & Categories (22) \\
\hline \multirow[t]{8}{*}{ Antecedents } & \multirow{4}{*}{$\begin{array}{l}\text { Distorted } \\
\text { mental self-image }\end{array}$} & Sense of having an ugly face \\
\hline & & Problems in facial appearance \\
\hline & & $\begin{array}{l}\text { Inappropriate interactions } \\
\text { with others }\end{array}$ \\
\hline & & Isolation \\
\hline & \multirow{2}{*}{$\begin{array}{l}\text { Hope to look } \\
\text { attractive }\end{array}$} & Need to receive attention \\
\hline & & Giving importance to beauty \\
\hline & \multirow{2}{*}{$\begin{array}{l}\text { Inappropriate } \\
\text { interactions } \\
\text { with family and } \\
\text { friends }\end{array}$} & Being outraged \\
\hline & & Reactions to family \\
\hline \multirow{9}{*}{$\begin{array}{l}\text { Effective } \\
\text { factors }\end{array}$} & \multirow{3}{*}{$\begin{array}{l}\text { Family's views } \\
\text { toward the problem }\end{array}$} & Attitudes and interactions \\
\hline & & Knowledge and awareness \\
\hline & & Socioeconomic level \\
\hline & \multirow[t]{2}{*}{ Social conditions } & $\begin{array}{l}\text { Attitudes of those around } \\
\text { and the community }\end{array}$ \\
\hline & & Culture \\
\hline & \multirow[t]{2}{*}{ Financial constraints } & High cost \\
\hline & & $\begin{array}{l}\text { Lack of financial support } \\
\text { by the government }\end{array}$ \\
\hline & \multirow[t]{2}{*}{$\begin{array}{l}\text { Hope for a better } \\
\text { future }\end{array}$} & $\begin{array}{l}\text { Confident and powerful } \\
\text { presence in the community }\end{array}$ \\
\hline & & Self-esteem \\
\hline \multirow[t]{3}{*}{ Mechanism } & \multirow[t]{3}{*}{$\begin{array}{l}\text { Challenges in the } \\
\text { family }\end{array}$} & $\begin{array}{l}\text { Uncertainty for the } \\
\text { outcomes }\end{array}$ \\
\hline & & Limited financial power \\
\hline & & Time-consuming treatment \\
\hline \multirow[t]{2}{*}{ Consequences } & \multirow{2}{*}{$\begin{array}{l}\text { Decision making } \\
\text { to undergo the } \\
\text { treatment }\end{array}$} & Information acquisition \\
\hline & & Funding \\
\hline
\end{tabular}

direct or indirect emphasis on looking more attractive. This was an objective sought by most of the clients. This category featured in two more sub-categories; receiving attention and giving importance to beauty. For example, they stated that:

It was really important for me to hear others talking about my attractive teeth in parties, I did not want to be so humiliated due to the projection of my teeth [...]. [P6]

I was always thinking how my teeth would appear aligned like those of my friends after undergoing orthodontic treatment. I wished to be like them and everyone would say how beautiful and fine my teeth were [...]. [P8]

\section{Inappropriate interactions with family and friends}

This category was one of the most influential ones in the decision-making process. Problems in the oral structure and the teeth could make clients feel uncomfortable and demonstrate the unpleasant feelings in their behaviors as well as interactions with families. Low threshold for tolerance and being outraged were among the cases mentioned by both patients and family members. In this respect, participants stated that:

I was always angry because I was not like other people. I thought that my mouth was not attractive and my lips were not fitting together [...]. I was obsessed with this thought, but whenever I had a chance to talk about this problem with my family, they used to say that it was nothing and that was just a fantasy [...]. [P15]

I was not in a good mood to speak with my family. They caused such a delay in my treatment. If they thought of this problem earlier, I would not be so much annoyed [...]. [P13]

\section{Family's views toward the problem}

Analysis of the clients' words revealed that one of the factors influencing the decision-making process for orthodontics was the family's views toward the problem. According to the clients' statements, many families did not care about malocclusion, especially those with a lower sociocultural level, and they considered orthodontic treatment only as a cosmetic therapy; however, some families regarded orthodontics as a treatment not only for beauty but also for health and well-being. In this regard, interactions between families and the community and other people and families could have their own effects. For example, participants stated that:

First, her father and I used to think that my daughter would like to undergo orthodontic treatment just for beauty and we used to say that was worthless because it costs a lot. But, we changed our minds as soon as we found that the given treatment could affect the stomach and the intestine problems [...]. [mother of P7]

I persistently told my family that I had to go to the dentist and arrange my teeth, but they used to say that they could not pay such a money for my beauty and they believed that lack of beauty does not matter [...]. [P4]

\section{Social conditions}

Among the other important factors found in the analysis of participants' statements were social conditions. The given category was derived from two sub-categories: attitudes by those around and the community as well as the culture. In this respect, most of the clients stressed the interactions between family and the community and stated that the views of relatives and those around had an impact on their views and 
thoughts as well as those of their families. Some participants also emphasized the positive effects and encouragements for them and their families to perform orthodontics, and others highlighted the importance of orthodontic treatment. In this respect, participants mentioned that:

My cousin and my neighbor's son had an orthodontic treatment. As they were meeting my dad, they used to say that your son needed orthodontics because his teeth were projected. So, my dad decided to take me to the dentist to brace them [...]. [P6]

Orthodontics is for the rich. I think no problem happens without it. My neighbor's child suffers from a worse condition, so there is no problem. I think orthodontic treatment is costly and insensible and also does not lead to any outcomes [...]. [P14]

\section{Financial constraints}

Another category extracted from the analysis of the participants' words was financial constraints. This category emerged from the sum of the sub-category of high cost and lack of financial support from the government. All the participants also emphasized that they were bearing a financial burden due to the high cost of living and especially orthodontics, and it was hard to meet the cost of this treatment. Moreover, families were reluctant to do this type of treatment owing to lack of insurance coverage and they considered it as a cosmetic remedy. In this regard, participants reiterated that:

I could not afford it; I had to sell my jewelry to pay the costs $[\ldots]$. [p12]

There were lots of financial troubles in my family and the insurance did not cover the orthodontic treatments. I did not say a word at all about it to my family. I worked and I paid for it [...]. [p4]

\section{Hope for a better future (core variable)}

Another factor that was going on throughout the process was hope for a better future as evidenced by a number of subcategory, including a powerful presence in the community and self-esteem. All the study participants emphasized to some extent on this category in their statements. This category was almost related to all the process concepts and represented itself as the core factor. In this regard, participants stated that:

I had many problems, but I saw that it was necessary for the future of my child because he wanted to get married and to show himself in the community. So, I tolerated all the difficulties and came orthodontics [...]. [P7]
I am young and I want to get married. This problem can affect my whole life and my relationships with other people. I told myself that I needed to try all the possible ways to make my teeth aligned [...]. [P11]

\section{Challenges in the family}

Another category extracted from the analysis of the statements by the clients was the challenges in the family. This category emerged from a series of three sub-categories; that is, uncertainty for outcomes, limited financial power, and time-consuming nature of the treatment. Analyzing the clients' statements also revealed that due to the need in the individuals to receive this treatment and the numerous financial problems in this domain, the involvement of the family and the kind of family members' perception of the problem had led to a tension in the family and made the decision-making process difficult. Therefore, the hope for a better future could persuade clients and their families to do orthodontics. In this regard, the mother of one of the clients added that:

When my daughter came and said that she wanted to do orthodontic treatment, I did not take it seriously at first. As I saw her insistence and stubbornness, I thought about the high costs, financial problems, and commutes to the dentist's, whether it would have a positive outcome or not, and finally about the way it could be good for her life [...] [mother of P5]

\section{Decision making to undergo the treatment} This category was the final result of the process obtained from the sum of sub-category, including information acquisition and funding. Eventually, the participants stated that they had attempted orthodontics after gaining information from different individuals, counseling with physicians, as well as efforts to provide medical cost.

\section{Conceptual model}

The decision making to undergo orthodontic treatment was a dynamic and multidimensional process in which antecedents, such as distorted mental self-image, hope to look more attractive, and inappropriate interactions with family and those around were the process-starters. In this process, the effective factors included family's views toward the problem, social conditions, financial constraints, and hope for a better future. Moreover, challenges in the family were the main mechanisms. Ultimately, the outcome of the decision-making process was established. 


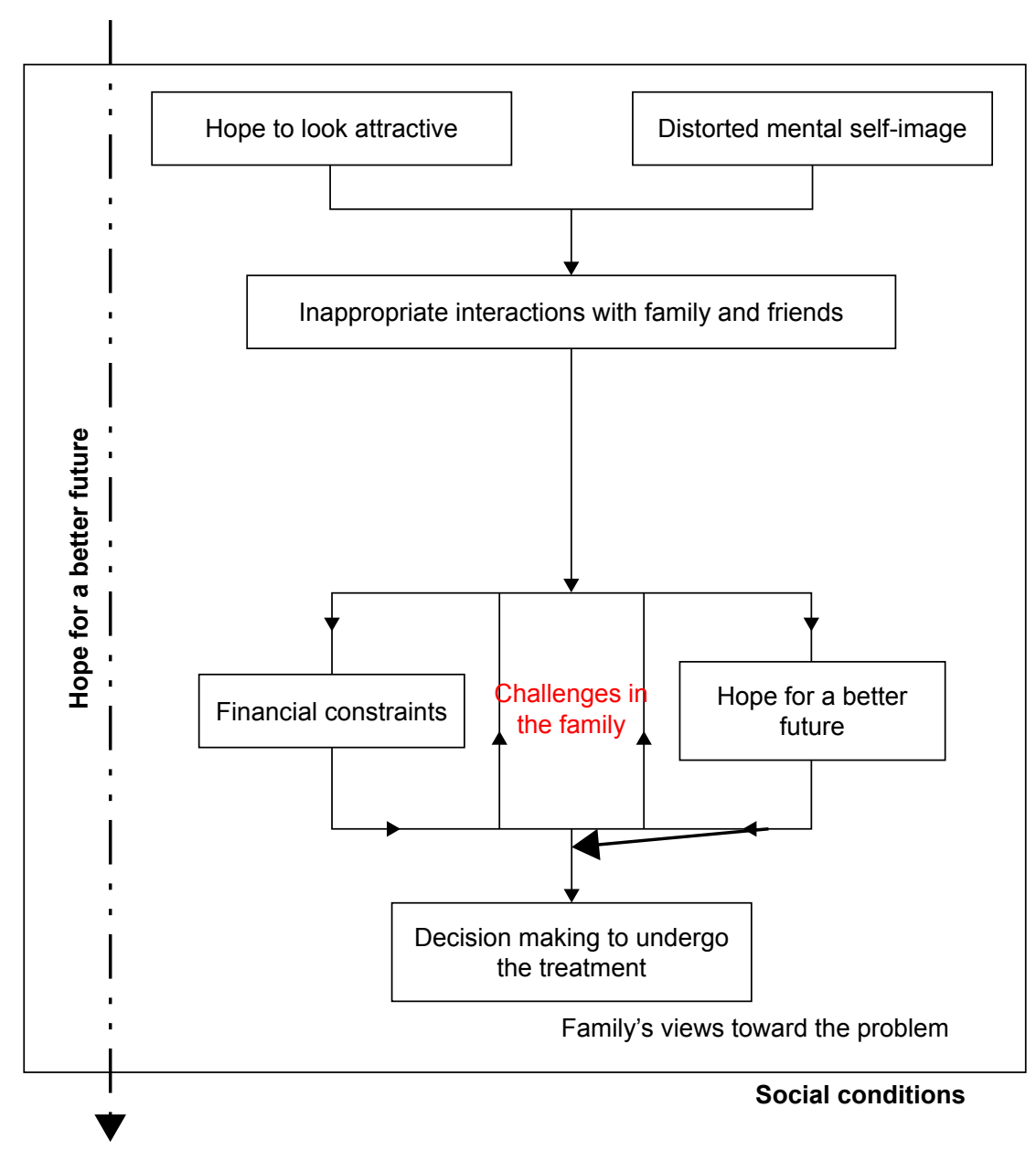

Figure I Conceptual model of orthodontic decision making.

Analysis of the data showed that problems with malaligned teeth could result in distorted mental self-image. Hope to look more attractive could also affect living and behavioral conditions. Contacts with people, interactions, and the effects that social communications could have on individuals had also made the clients feel the need for orthodontics. Moreover, the hope for a better future would have a great influence on such a decision making. Although challenges in the family, family's views toward the problem, social culture, social interactions, and financial constraints could also initially lead to family's opposition with orthodontic treatment, there was hope for a better future. Hope for a better future and one's intentions for a high-profile presence in the community, cause communication problems and tension in the family. Love and passion for children, and hope for a better future, along with financial constraints, treatment problems, and the probability of not achieving the desired outcomes had also placed families in a tension phase. Finally, the core factor of hope for a better future had persuaded individuals and families to perform orthodontics. In this respect, they referred to knowledgeable individuals, physicians, and experienced people to seek for information and ultimately pay the cost of orthodontic treatment (Figure 1).

\section{Discussion}

This study was conducted to determine the decision-making process to undergo orthodontics. The results showed that the factors, including distorted mental self-image, hope to look more attractive, inappropriate interactions with family and those around, family's views toward the problem, social interactions, financial constraints, and hope for a better future are among the factors influencing the given process. The core factor in this regard was hope for a better future.

The results of the study also revealed that the participants (parents and, in some cases, the clients) had seen a better future at all stages of the process and believed that there would not only be changes in appearance and beauty but also better job and marriage opportunities by performing the orthodontic treatment. This reason was considered as a 
factor for a sense of being valued in people. In this regard, the results of other studies indicated an enhanced sense of being valued in orthodontic patients. ${ }^{3,10}$ Besides, the findings of the related investigations suggested that the beauty of the mouth and the teeth could play an important role in raising self-confidence and acceptance of people in communities. ${ }^{1,6,16}$ The results of a qualitative research by Trulsson et al revealed consistency with social norms as a core variable in making decisions to undergo orthodontics. ${ }^{17}$ Psychologically, the sense of well-being could also have a very important role in decision making to do orthodontic treatments, ${ }^{18}$ in line with the results of the present study.

Moreover, the findings of this study showed that distorted mental self-image and hope to look more attractive were the two core factors to start the decision-making process because well-aligned teeth and beautiful smiles could make a person more confident and powerful in social encounters. However, malpositioned and protuberant teeth could have a negative effect and decrease self-confidence. ${ }^{19,20}$ There is always a constant relationship between the beauty of appearance and social performance such that this kind of malocclusion could bring about the loss of social performance in these individuals. ${ }^{21}$ A person's perception of their dental appearance can be also considered as a psychological reason behind the desire to perform orthodontics. ${ }^{8}$ In this connection, many studies have pointed to the fact that having a distorted mental self-image and an incentive to have a better appearance are among important factors affecting the decision-making process for orthodontic treatment. ${ }^{2,3,10}$ In a study conducted in Isfahan city in Iran, a significant relationship was found between self-confidence, tendency to undergo orthodontics, satisfaction with the arranged appearance of the teeth, and the degree of real need for orthodontics. Moreover, it was concluded that most of the university students in this study were satisfied with the arrangement and appearance of their teeth; thus, the higher the levels of education, the higher the self-confidence and the lower the demand for orthodontic treatment. ${ }^{19}$ The results of the present study were also similar in this respect; in fact, dissatisfaction with one's beauty and distorted mental self-image were considered among the main factors starting the process.

Moreover, the results revealed that the clients were suffering from behavioral problems due to having a distorted mental self-image and the hope of becoming more attractive. Moreover, they had even difficulty in their behavioral interactions with their families to win their satisfaction. In this regard, studies have shown that oral and teeth problems can affect psychosocial aspects of individuals, reduce their quality of life, lead to the decreased presence of these people in the community, and consequently have a negative impact on interpersonal relationships. ${ }^{3,22}$

Furthermore, the results of this study suggested that family's views toward the problem, financial constraints, as well as psychological and behavioral pressures imposed by the clients to do orthodontics had challenged families. The results of other studies also confirmed the findings of this study. ${ }^{10}$ Moreover, other investigations shed light on the role of family and particularly mothers and parents in decision making for such a treatment. ${ }^{11}$ The role of family was similarly highlighted in this study because familial interactions and family support for members in Iran, particularly in its western regions, are of utmost importance. In such areas, family members sometimes live with their families and receive economic, psychological, and social supports up to the age of 30 years and even until marriage.

The findings also revealed that the knowledge of clients and their families about orthodontics and, eventually, the future of the treatment were among factors interrupting orthodontic treatment or causing withdrawals by clients and families. The results of other studies also confirmed the findings of the present study. In this respect, Knapp et al emphasized that clients and their families needed information and awareness about decision making for orthodontic treatment and its consequences. ${ }^{23}$

There were several limitations to this study. Most of the clients were reluctant to record their interviews. This issue was resolved to some extent after explaining to the clients and assuring them that their personal information will remain confidential. Given the clients' monthly visits to the clinics in this study, cell phones were used to have a proper communication with the participants and they were contacted by the researchers whenever necessary and according to the previous arrangements. The participants were also allowed to contact the researchers (the first and the second authors) round the clock.

\section{Conclusion}

The study revealed that numerous factors could affect the decision-making process for the use of orthodontic treatments. Most of the clients with mild problems in the arrangement and the form of their teeth highlighted the core factor of hope for a better future. Families also accepted many challenges, including high cost and repeated follow-ups due to the importance of beauty and meeting their children's sense of satisfaction. Improving family context and structure could similarly have their own effects on making decisions 
to adopt this treatment method. Moreover, the majority of the families underscored their children's sense of satisfaction and that of oneself, in the case they were the clients, as an important factor. Among the other factors affecting the decision-making process were keeping up with others and being afraid of derisions by others.

\section{Acknowledgments}

We hereby express our gratitude to the contributors, researchers, orthodontic clinics in the city of Kermanshah, as well as the Vice-Chancellor's Office for Research and Technology at Kermanshah University of Medical Sciences. All the participants, individuals, and organizations are also appreciated for their collaboration with this study. This study was supported by a grant from the Deputy for Research and Technology, Kermanshah University of Medical Sciences, University Research Committee (Grant No 95094).

\section{Consent to publish}

Our manuscript does not contain any individual's data in any form (including individual details, images, or videos); thus, there is no need for any publishing consent.

\section{Availability of data and materials}

The datasets used and analyzed during the current study are available from the corresponding author on reasonable request.

\section{Disclosure}

The authors report no conflicts of interest in this work.

\section{References}

1. Alanko OM, Svedström-Oristo AL, Peltomäki T, Kauko T, Tuomisto MT. Psychosocial well-being of prospective orthognathic-surgical patients. Acta Odontol Scand. 2014;72(8):887-897.

2. Kiyak HA. Does orthodontic treatment affect patients' quality of life? $J$ Dent Educ. 2008;72(8):886-894.

3. De Baets E, Lambrechts H, Lemiere J, Diya L, Willems G. Impact of self-esteem on the relationship between orthodontic treatment need and oral health-related quality of life in 11- to 16-year-old children. Eur $J$ Orthod. 2012;34(6):731-737.

4. Danaee S, Fijan S, Mohammadi N, Zadeh R. Evaluation of relationship between orthodontic treatment need according Dental Aesthetic Index (DAI) and student's perception in 11-14 year old students in the city of Shiraz in 2012. Int J Res Med Sci. 2015;3(5):1056-1060.
5. Bernabé E, Sheiham A, Tsakos G, Messias de Oliveira C. The impact of orthodontic treatment on the quality of life in adolescents: a casecontrol study. Eur J Orthod. 2008;30(5):515-520.

6. Borzabadi-Farahani A. A review of the evidence supporting the aesthetic orthodontic treatment need indices. Prog Orthod. 2012;13(3): 304-313.

7. Caglayan F, Altun O, Miloglu O, Kaya MD, Yilmaz AB. Correlation between oral health-related quality of life (OHQoL) and oral disorders in a Turkish patient population. Med Oral Patol Oral Cir Bucal. 2009;14(11):e573-e578.

8. Avinash B, Avinash BS, Shivalinga BM, Jain S. Body dysmorphic disorder in orthodontic patients. World J Dent. 2013;4(1):56-59.

9. Xie X, Wang L, Wang A. Artificial neural network modeling for deciding if extractions are necessary prior to orthodontic treatment. Angle Orthod. 2010;80(2):262-266.

10. Sadat-Marashi Z, Scolozzi P, Antonarakis GS. Perceptions of Young Adults Having Undergone Combined Orthodontic and Orthognathic Surgical Treatment: A Grounded Theory Approach. J Oral Maxillofac Surg. 2015;73(12):2391-2398.

11. Kazancı F, Aydoğan C, Alkan Ö. Patients' and parents' concerns and decisions about orthodontic treatment. Korean J Orthod. 2016;46(1):20-26.

12. Johansson L. Shared decision making and patient involvement in choosing home therapies. J Ren Care. 2013;39(Suppl 1):9-15.

13. Speziale HS, Streubert HJ, Carpenter DR. Qualitative Research in Nursing: Advancing the Humanistic Imperative. 5th ed. Philadelphia, PA; Wolters Kluwer Health/Lippincott Williams \& Wilkins; 2011.

14. Strauss A, Corbin JM, Corbin J. Basics of Qualitative Research: Techniques and Procedures for Developing Grounded Theory. 2nd ed. Thousand Oaks, CA: SAGE Publications; 1998.

15. Polit DF, Beck CT. Nursing Research: Principles and Methods. 7th ed: Philadelphia, PA: Lippincott Williams \& Wilkins; 2004.

16. Abed Al JF, Cunningham SJ, Croft N, Johal A. A qualitative study of the early effects of fixed orthodontic treatment on dietary intake and behaviour in adolescent patients. Eur J Orthod. 2012;34(4):432-436.

17. Trulsson U, Strandmark M, Mohlin B, Berggren U. A qualitative study of teenagers' decisions to undergo orthodontic treatment with fixed appliance. J Orthod. 2002;29(3):197-204.

18. Broder HL, Phillips C, Kaminetzky S. Issues in decision making: Should i have orthognathic surgery? Semin Orthod. 2000;6(4):249-258.

19. Amnaie A, Nasiri M, Adib M, Shirvani A. Relationship between self-concept and satisfaction with tooth alignment and demand for orthodontic treatment and professionally determined orthodontic needs. J Isfahan Dental School. 2012;7(5):656-661. Persian.

20. Sarver DM, Rousso DR. Surgical procedures to improve esthetics when orthognathic surgery is not an option. Am J Orthod Dentofacial Orthop. 2004;126(3):299-301.

21. Cash TF. Body image: past, present, and future. Body Image. 2004; 1(1):1-5.

22. Choobineh A, Neghab M, Hasanzade J, Rostami R. Comparative assessment of dentists' psychological health status in Shiraz with their physicians counterparts using general health questionnaire (GHQ-28). J Dental Med Tehran Univ Med Sci. 2013;25(4):290-296.

23. Knapp C, Madden V, Feeg V, Huang I-C, Shenkman E. Decision Making Experiences of Adolescents Enrolled in Children's Medical Services Network. In. University of Florida: Institute for child health policy; 2008.
Patient Preference and Adherence

\section{Publish your work in this journal}

Patient Preference and Adherence is an international, peer-reviewed, open access journal that focuses on the growing importance of patient preference and adherence throughout the therapeutic continuum. Patient satisfaction, acceptability, quality of life, compliance, persistence and their role in developing new therapeutic modalities and compounds to optimize

\section{Dovepress}

clinical outcomes for existing disease states are major areas of interest for the journal. This journal has been accepted for indexing on PubMed Central. The manuscript management system is completely online and includes a very quick and fair peer-review system, which is all easy to use. Visit http://www. dovepress.com/testimonials.php to read real quotes from published authors. 